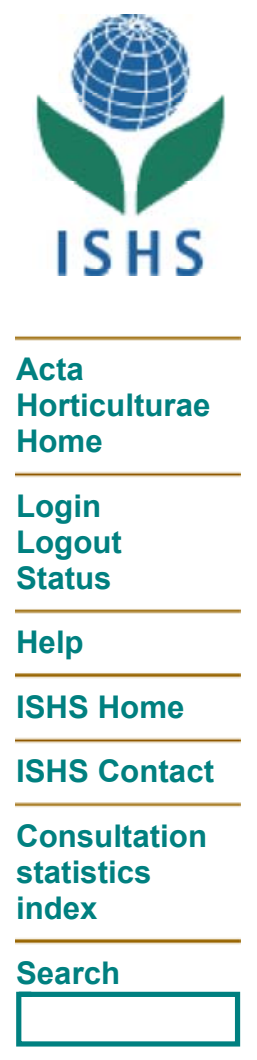

ISHS Acta Horticulturae 1018: I International Symposium on Organic Matter Management and Compost Use in Horticulture

\title{
CONCEPT FOR QUALITY \\ MANAGEMENT TO SECURE THE \\ BENEFITS OF COMPOST USE FOR SOIL AND PLANTS
}

\author{
Authors: J.G. Fuchs, A. Berner, J. Mayer, K. Schleiss \\ Keywords: compost quality, compost utilization, Swiss guidelines \\ 2010
}

Abstract:

Use of quality compost can have an important positive impact on soil fertility and plant growth and health. For example, it increases soil humus and improves soil structure and suppressivity towards plant diseases. To obtain these positive results, it is important that the compost quality is appropriate for each use. If used inadequately, the impact of compost can also be negative.

The compost producer should be responsible for the quality of his products, and has to communicate the properties of his composts to the users. But to be successful, the compost users have to communicate to the producers the manner in which the compost is to be used. To support compost producers and users in this process, the Swiss producers of compost and digestate published a new quality guideline for compost and digestate in 2010. Five product classes are defined in this guideline: digestate liquid, digestate solid, compost for agricultural use, compost for horticultural use in the open field, and compost for covered cultures. The guideline requires compost producers to establish a quality concept, ranging from collection of green manure to utilization of the products.

Public relation activities are then important to communicate this guideline. Communication between compost producers, compost users and other stakeholders is important to improve the potential of compost use and to develop further application possibilities.

- Full Text (PDF format, 176852 bytes)

- Citation

- Translate

\begin{tabular}{l}
\hline Sprache auswählen $\vee$ \\
Powered by Google Übersetzer
\end{tabular}

Download Adobe Acrobat Reader (free software to read PDF files)

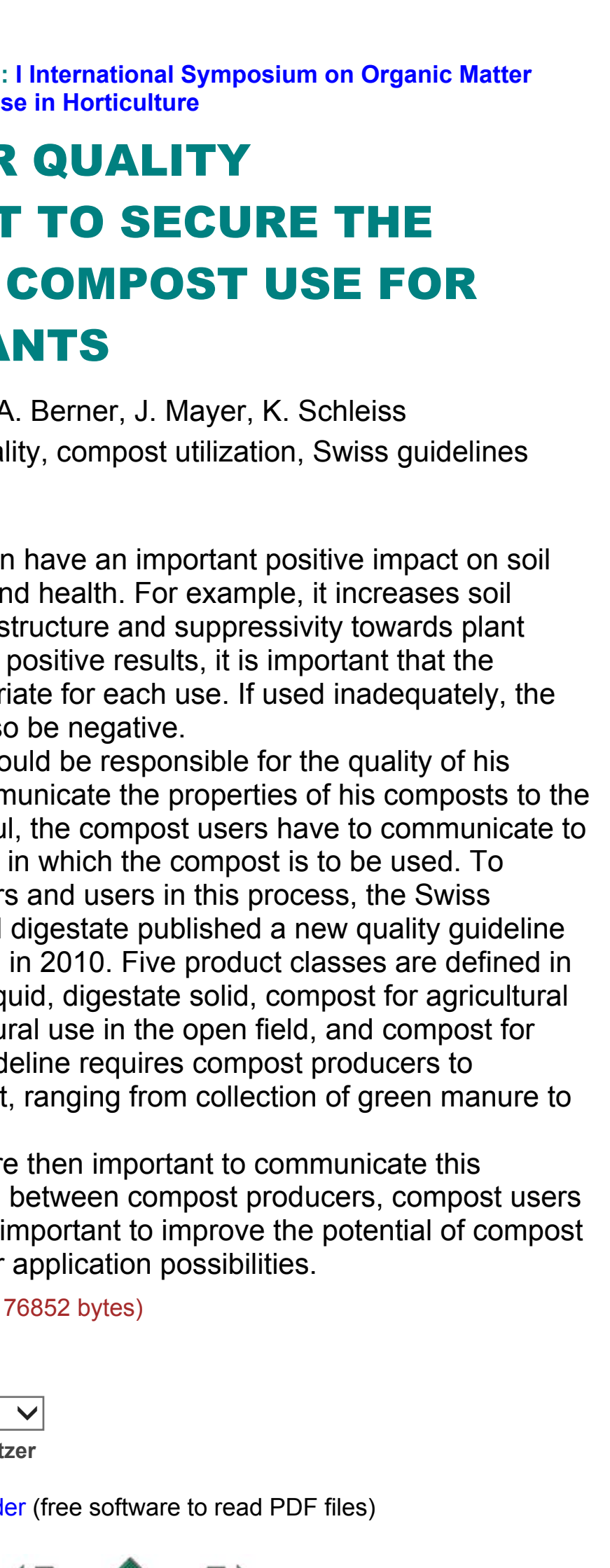

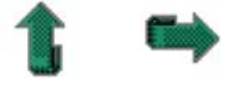


